SMART Journal, Volume 6, No. 2, August 2020, Page 82- 97

ISSN Cetak : :2356-2048

ISSN Online : 2356-203X

\title{
RETHINKING THE ROLE OF ENGLISH LECTURERS IN THE DIGITAL ERA
}

\author{
Disa Evawani Lestari \\ Faculty of Humanity, President University \\ Email Correspondence: disa.silaen@president.ac.id
}

\begin{abstract}
Along the era of rapid advancement on the performance of Artificial Intelligence, there have been intense discussion and debates among educationists about the future of human teachers and AI teachers. It is intriguing to listen to students' perspectives on the roles they expect from their teachers, especially in learning English subjects, when abundant resources are available online within their fingertips. To serve that purpose, 160 students were recruited as research participants. Data were collected through questionnaire and interview. The results indicated that students perceive their teachers as someone to guide their learning by providing good online resources and immediate feedback.
\end{abstract}

Keywords: Lecturers, roles, digital

\section{INTRODUCTION}

Technology shifts civilization. As someone born and raised in the end of $20^{\text {th }}$ century, millennial have experienced that technology has changed human being routine and needs in many ways. In the late $20^{\text {th }}$ century, the access of information was not as massive as today. People were still tame, patient, and sufficed with the "slow-paced" life.

With the increasing use of blended learning approaches in classroom, various kinds of technologies are incorporated to provide digital teaching and learning resources to support students. Education nowadays involves technology on its daily basis. Teacher is not the only source of information anymore but more precise information is now provided in our fingertips; there has even been a phrase "Google

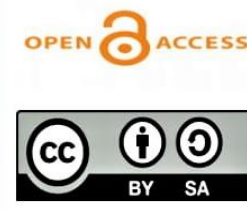

Creation is distributed under the Creative Commons License Attribution 
it" in the term of asking someone to seek certain information on Google. Learning becomes more colorful and visual and the unexpected challenge grows.

Many schools or universities have developed its own online learning which can reduce the direct interaction between educators and students in the classroom. It is not only about how to create an intelligent students cognitively but also how to create students who are able to deal with billions of information provided on the internet, to choose which information is fact or hoax, and to focus. Furthermore, social-emotional intelligent is an important issue to develop in this digital era since millennial and postmillennial will be responsible for taking the role of active contributors to the future world and its citizens.

In addition to that, because of the sprouting emergence of social media platforms, exposure to English language use in daily life context is higher. One may live in the Expanding Circle countries Kachru as cited in (Mollin, 2006), but manage to be exposed to, or even use, English just like how English is used for daily communication in the Inner and Outer Circle countries just by using a smartphone. It is easy to notice how young people these days confidently share or comment on an issue on social media using English.

Educators must realize that in order to survive the civilization, one must adapt and have the skills that are necessary in that time. According to some researchers, the era of $21^{\text {st }}$ century is the creativity and digital era. When all information can be accessed easily, some questions appear amidst this rapid change; if all knowledge can be accessed within our students' fingertips, to what extent do millennial and postmillennial children still need teachers in the classroom? What are the roles of teachers in the classroom that technology does not provide? There have been some studies discussing about education in the digital era which suggest that an educator's role is to be a facilitator, but do our students agree with that consensus? Is it culture-bound? 
Since most of the existing studies are conducted in western countries, in which students' learning independence is high, and students and teachers are deemed equal, it is really intriguing to listen to students in Indonesian university's perspective on the roles which they expect their lecturers to take.

Along the era of rapid technology advancement on the performance of Artificial Intelligence (henceforth $\mathrm{AI}$ ), there have been intense discussion and debates among educationists about the future of human teachers and AI teachers. Ljosa (1998), long before online learning platforms started to sprout, has predicted that "the new technology will not change the work of the teachers fundamentally, but will, nevertheless, have profound impact on how the various approaches to teaching can be implemented in radically different technological and organizational environments". On the other hand, in a more recent study, Susskind \&Susskind (2015) argued that technology will transform the work of human experts, including teacher profession. They further elaborated that, for now, human teachers and AI teachers will still operate in parallel, but in the longer run, gradual dismantling will occur, leading to the domination of AI teachers.

Regardless from the ongoing debate, however, there seems to be a consensus among those researchers that both human teachers and AI teachers will co-exist, but in various levels of dominance. Therefore, it is emphasized that schools need transformation of pedagogy and practice as well as broaden learning experiences (Tan, 2013) and better address students' diverse learning needs (Poon, Kong, Yau, Wong \& Ling, 2017). Tan's idea indicates that the person behind the scene - scene here means learning process - is still important to design an effective teaching and classwork who will still prepare the lesson planning and continuous assessment for the students, which is something that cannot be completely done by technology only

\section{The Roles of Technology.}


Courville (2011) states that the role of technology, in a traditional school setting, is to facilitate, through increased efficiency and effectiveness, the education of knowledge and skills. Nowadays, learning can be done online as well. Many terms have been developed such as blended learning, distance learning, online course and many more. Courville adds that it is no longer necessary for students to have geographical proximity to a university in order to pursue higher education and certification. This trend towards online classes and educational opportunities has even become so prevalent that there are universities which consist of online classes only, allowing students to complete an entire course of study through distance learning (Dempsey \& Van Eck, 2012). Second, the use of distance learning is not limited to the university setting, but also found in school site, district, and state levels of professional development for teachers, with the emergence of web-based conferences and seminars. This indicates that online learning becomes one method of teaching because, for some reasons, it can diminish things that can be some obstacles, such as course cost, geographical restraints, and time restraints (Means, Toyama, Murphy \& Jones, 2009).

According to the office of technology of U.S Department of Education (28, 2017), technology can empower educators to become co-learners with their students by building new experiences for deeper exploration of content. This enhanced learning experience embodies John Dewey's notion of creating "more mature learners." Side-by-side, students and teachers can become engineers of collaboration, designers of learning experiences, leaders, guides, and catalysts of change. Following are some descriptions of these educator roles and examples of how technology can play an integral part. Technology does not change the role of educators yet together teacher, students, and technology collaborate to explore new experiences in learning. 
Lee, Chow, Button \&Tan (2017) conducted a study which focuses on the use of nonlinear pedagogy in Physical Education. Nonlinear pedagogy is learner-centered method emphasizing autonomy and guided discovery. Findings from this study, which involves primary school students, show that such pedagogies facilitate social skills and teamwork. The application of nonlinear pedagogies essentially gives students more freedom to explore, resulting in greater perceived competence in their learning, as well as more opportunities to demonstrate problem-solving and creativity. Our students need inclusive pedagogy which is the integration of qualified learning with technology to meet the standard that is demanded by the $21^{\text {st }}$ century.

\section{The Roles of Teachers}

From the perspective of the Triarchal Instruction Model proposed by Guey, Cheng \& Shibata (2010), the roles of teachers can be categorized as behavioral, cognitive, and humanistic work. This is based on the more explicit roles proposed much earlier by Bjorgen (as cited by Ljosa, 1998). These explicit roles are: the sculptor, the entertainer, the coach, and the manager. The following is the explanation of each role:

The sculptor role is to be fully responsible for the presentation of all relevant materials. He determines the schedule and the curriculum concepts as well as the work of the students. This type does not pay much attention to motivate the students as it is considered the students' responsibility to learn what the teacher tells them. The focus of classroom interaction is to clarify the content of the textbooks and to correct students' work. The entertainer role resembles the role of an actor, responsible for arousing students' interest so that it is easier for the students to understand the subject. He maintains an active dialogue in presenting or accentuating his view. 
1. The coach acts as a catalyst to make the students get the work done by themselves and to maximize their individual attainment. He is clear on the subject goals, assessment criteria, and provides supportive feedback.

2. The manager perceives the classroom as a working place, thus manages students to work in groups. In doing so, he acknowledges the uniqueness of each student and their differences. He is responsible for making sure that all students can co-operate one another to achieve the best possible result.

\section{Research Gap: The Integration of Technology into Classrooms}

Tan excerpted Richard Elmore term "Core of Educational Practice" to visualize that teachers must understand the students' nature of learning. In the beginning of this research, it has been explained that students of $20^{\text {th }}$ century have many differences in nature with students of $21^{\text {st }}$ century. What matters the most in this century is the ability to communicate, collaborate, being creative, and have critical thinking. In addition to that, they are so close to technology that the absence of such things in the learning process can lead to unfamiliarity and less motivation (Israel, 2015). Therefore, teacher must adapt and be able to provide these needs to their students to experience the learning process and achieve the result at its best.

In general, students nowadays are often assumed to be digital natives or are more familiar with technology. This familiarity to technology is often interpreted as them being able to make use of online resources for an independent learning with very little, if not any, guidance from their teachers (Prensky, 2001; BennertMaton\&Kervin, 2008).

However, some more recent studies reveal that such claim seems to be overrated for some reasons. First, students tend to be overwhelmed with the abundant number of contents on the Internet (Kim \& Frick, 2011). Second, it is claimed that technology provides students with too much available information which increases students' 
passivity and interferes with the active learning pedagogy that should be the hallmark of a law school classroom (Caron\& Gely, 2004). In addition to that, it is also found that English language proficiency impedes online learning success, especially those who do not speak English as their first language (Shariman, Razak, \& Noor, 2012).Furthermore, in a more recent study, Selwyn (2016) rings the bell to balance our enthusiasm for what we consider might be achieved through technology-enabled learning, with the unsatisfactory realities of students' encounters with digital technology. Based on his survey of 1,658 undergraduate students from two Australian universities, his study finds out that there are four distinct digital downsides that students often see as the source of frustration and confusion that drag them down from effective learning.

In conclusion, those studies suggest that students' digital nativeness should not be overrated and that teachers should step in and play their 'newly adjusted teacher's roles' responding to the unique challenges students encounter when learning with online resources. Hence, the researchers believe that research into students' perspectives should be one of the fundamental bases to formulate effective and customized teachers' roles. This is the gap that this research tries to fill in. By listening to the opportunities and challenges students encounter, teachers can better rethink, re-question, and redesign their approach in teaching in order to achieve greater learning attainment.

Thus, this study seeks to achieve aforementioned purposes, and the issues to be discussed in this study can be summarized in the following research questions:

1. To what extend does the Internet support students' learning activities for English subject?

2. What roles do students expect their lecturers to take in their learning process in the midst of abundant online resources? 


\section{RESEARCH METHOD}

\section{Research Design}

The current study employs a mixed method approach to put quantitative and qualitative data together. The study adopts such triangulation design to allow the researchers to collect both quantitative and qualitative data concurrently and to figure out if there is convergence, differences, or some combination (Cresswell, 2009).

\section{Participants}

The study was conducted from April-November 2019 involving 160 students in President University, West Java. There are sixteen study programs in this university, ranging from school of business, school of humanities, and school of computing. All of those study programs will be represented by equal number of students. This purposive sampling was implemented to capture the extent to which the incorporation of technology in the learning process varies across majors, which might then affect students' responses on their perceptions on the roles of lecturers. Prior to the distribution of questionnaire, all students were provided with the consent form, the types of lecturers' role, and the overall picture of the research significance.

\section{Instruments}

Questionnaire and interview were used to collect data in this research. Prior to the distribution of research instruments, all research participants were gathered and informed about the research purposes. They were then given an informed consent form as well as the introduction to the theories used in this research, including the four types of teachers' roles and the four types of learning styles. Only after the study framework was understood was the data collection started.

The questionnaire (see Appendix 1)was distributed online and designed based on the theory of roles of lecturers in teaching and learning process (Guey et al., 2010). The questionnaire consists of 15 closed-ended questions using a six-likert scale and 
three open-ended questions. The questionnaire was administered to capture the intensity of technology use in their classrooms, the benefits and challenges of using online learning resources and the roles they wish their teachers take. After that, an interview was conducted to 32 students. The interview (see Appendix 2), which consists of five questions, aimed to gain in-depth explanation and description on the roles of lecturers in the learning process given that there have been abundant number of resources online which might have replaced some of the roles of lecturers throughout their learning process.

\section{Data Analysis}

The data from students' closed-ended questionnaire was statistically computed to find out the percentage of each statement and then were interpreted descriptively. The interview data were transcribed and analyzed for repeating key features to sharpen and confirm the ideas which have been gathered through questionnaire.

\section{RESULT AND DISCUSSION}

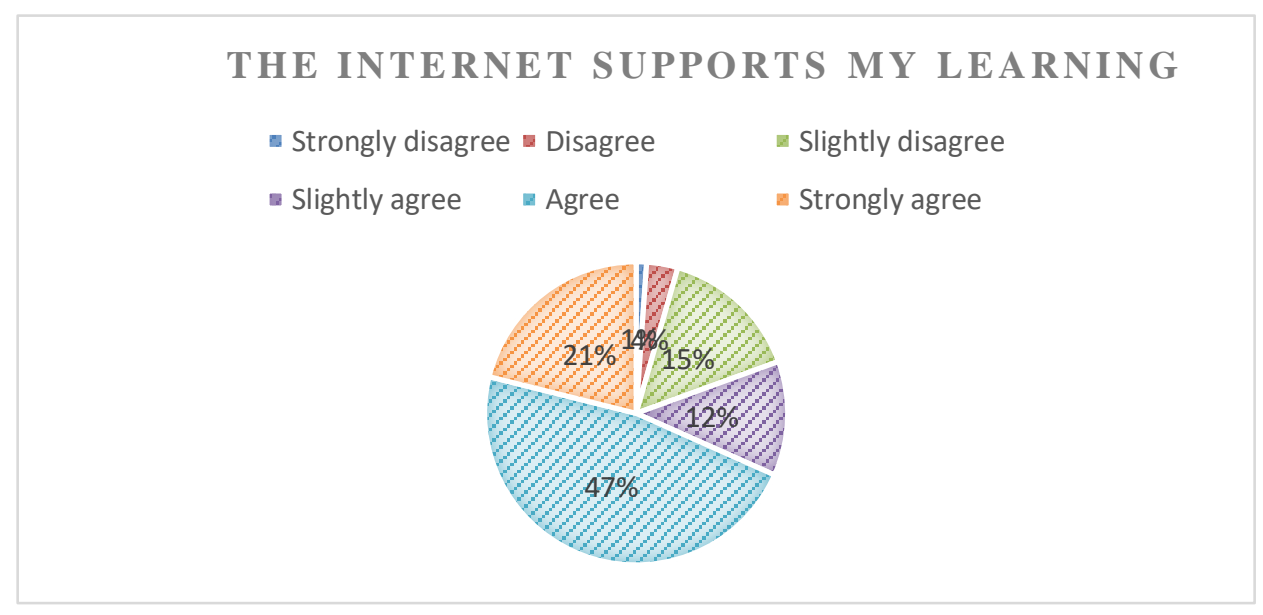

Diagram I: How Much the Internet Supports Students' Learning? 
As can be observed in the pie chart, 145 over 180 (80.5\%) participants reported that the Internet has supported their learning. It was further claimed that the ease of learning through the Internet is due to the instant answer they get just by typing the questions they have in the search engine. This is in line with the previous study conducted by Palocsay, White \& Zimmerman (2004).They explained that the Internet has become a platform for individuals to search information, understanding and solutions.

On the other hand, the 35 students who did not seem to benefit from the Internet further reasoned that they were easily distracted when learning with their gadget or computer with the Internet connection. The sources of those distractions include pop-up advertisements, social media notifications, unstable connection, and difficulty to stay focused on getting the information they need.

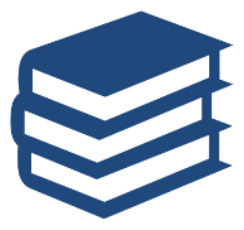

Individual Reading

$23 \%$

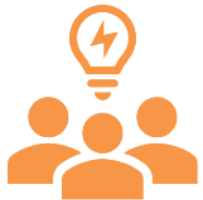

Group Discussion

$81 \%$

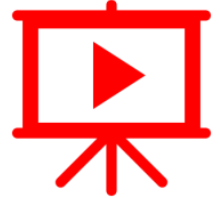

Watching Videos

$73 \%$

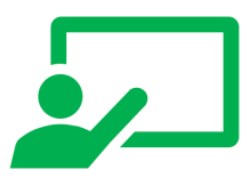

Attending Lectures

$36 \%$

Diagram 2: Students' Learning Preferences

From the figure above, it is clearly seen that millennial students have an inclination for learning through group discussion and watching videos/visuals. Inclination toward the former looks like a surprising fact. Millenials' addiction to gadgets is often associated to their tendency to be isolated to their surroundings. Interestingly. However, when it comes to making sense of complex issues or abstract ideas, and solving complicated problems, millennial love working in groups, 
particularly small group. This similar thing was admitted by more than two-thirds of the interviewed participants. This might be linked to their difficulty to sustain concentration when working by themselves (Marcus, 2011), which could also explain the participants' reluctance to do individual reading (23\%).

In addition to that, millennial' inclination toward watching videos echoes Tapscott's (2009) findings which also acknowledge that millennial have relatively more advanced visual memory and visual processing skills compared to the previous generations. Attending lecture, which is viewed by $33 \%$ of the participants as a long boring one-way speech by the lecturers, often does not incorporate the projector technology to display interactive presentation slides. And if presentation slides exist, they are often in a form of long words rather than a visual aid which provides clearer picture of the topic being discussed.

\section{Expected Roles of Lecturers}

Accommodating discussion, one of the most expected roles lecturers to take is to accommodate discussion $(81 \%)$. This means providing a more interactive discussion during classroom meetings, not only one-way lecture. In other words, ideas do not only come from the lecturers (one way), but two ways, in which students are given the opportunity to voice their thoughts and gain feedback from their lecturers and peers.

Providing immediate and frequent feedback, It has been discussed that millennial "thrive in situations where expectations are made explicit and ambiguity is limited"(Moore, 2012). In other words, they expect room for creativity and trial for error. They are also often described as relaxed type of learners who like to experiment and learn by doing, not being afraid of making mistakes. Therefore, they do not try to reach perfection and prefer to start with whatever level they are and expect the 
lecturers to provide immediate feedback. This impatience might be the cause of instant gratification of the fast Internet.

\section{Guiding Learning}

Students may develop frustration due to the digital divide between them and their lecturers. When lecturers are not up to date in their technology, they(especially those from previous generation) may not have adequate, if not equal, digital literacy rate by not incorporating open online library to find more recent facts about the current issue in their field, but instead, rely on the university library which provide books talking about the old less irrelevant issues students might not relate to. Another example, 83 participants reported, is the policy to submit printed work rather than online file shared on Google Drive, through which a thesis adviser can give comments on the advisee's work at his/her convenient time without asking the student to come to campus and wait for several hours due to the busy schedule of the adviser for thesis supervising appointment. Instead of guiding students' learning, these lecturers have given the students some frustration which might lead to a distrust and disrespect which might distract them from gaining knowledge from their lecturers.

Just over half of the participants (83) acknowledged that they seem to be easily distracted when surfing online, especially when there is no or only limited guidance given about the website to visit. Goggling the keywords to find the perfect source forces students to check the appearing results one by one, this is very time-consuming. In addition to that, they will also be distracted by the less relevant but seemingly interesting article, and before they know it, they have spent hours of being exhausted reading something not really relevant to what they need. Therefore, the role of lecturers in prescribing reliable websites is crucial.

2. Assigning more group work 
While millennial are often praised by their multitasking skill, they seem to struggle to sustain concentration in a long period of time by themselves due to that skill. Consequently, putting them to work in group is one way to keep them on the right track to approaching their task accomplishment (74\%). In addition to that, some argue that group work gives them a sense of social task fulfillment which they cannot get online $(68 \%)$.

From the descriptions above, it can be concluded that the roles of lecturers millennial expect from in the midst of abundant online learning resources are combination of Coach and Manager types described by Ljosa (1998), which has been reviewed in Literature Review Chapter.

If Human Teachers Would Ever be Replaced by AI

About three-quarters of the interviewed participants (78\%) argue that human teachers would never be replaced by machines or AI robots. Their reasons vary, from highlighting the importance of discussion/negotiation, giving constructive and understandable feedback, to giving them motivation. On the other hand, $22 \%$ of them explain that it is possible that human teachers will be replaced as they are more accurate, fast, automatic, and well-structured.

\section{CONCLUSIONS}

The changing landscape of millennial' world has been indicated that there is a strong need to adapt teaching and learning practices to millennial lifestyle. In the future, this generation is expected to be able to work with the Internet and to utilize it for maximizing potentials and more efficient use of time, energy, and resources. However, they need a patron to guide them.

Digital divide between the lecturers and students is clear in this study and has led to several unintended result. Consequently, lecturers are expected to have 
adequate, if not better than their students, digital literacy skill to guide them distinguishing reliable source of information, distinguishing facts and hoaxes, and honing their critical thinking skills. Students might seem to be more digital literate than their lecturers, but they still lack of critical thinking and content knowledge basis.

\section{REFERENCES}

Bennett, S., M. K.. \& Kervin, L. (2008). The 'Digital Natives' Debate: A Critical Review of the Evidence. British Journal of Educational Technology. Vol 39: 775-786.

Caron, P. L., \&Gely, R. (2004). Taking Back the Law School Classroom: Using Technology to Foster Active Student Learning. J. Legal Education.Vol. 54. 551.

Courville, K. (2011). Technology and its use in Education: Present Roles and Future Prospects. The 2011 Recovery School District Technology Summit . Vol. 5. 19.

Cresswell, J.W. (2009). Research Design: Qualitative, quantitative, and mixed Methods Approaches. California: SAGE Publications, Inc.

Dempsey, J. V., \& Van Eck, R. N. (2012). E-learning and instructional design. Trends and Issues in Instructional Design and Technology, Vol. 2. 281-289.

Guey, C. C., Cheng, Y. Y., \& Shibata, S. (2010). A Triarchal instruction model: integration of principles from Behaviorism, Cognitivism, and Humanism. Procedia-Social and Behavioral Sciences. Vol. 9, 105-118.

Israel, M. J. (2015). Effectiveness of integrating MOOCs in traditional classrooms for undergraduate students. The International Review of Research in Open and Distributed Learning. Vol. 5. 16.

Kim, K. J., \& Frick, T. W. (2011). Changes in student motivation during online learning. Journal of Educational Computing Research, Vol. 1. 1-23. 
Lee, M. C. Y., Chow, J. Y., Button, C., \& Tan, C. W. K. (2017). Nonlinear Pedagogy and its role in encouraging twenty-first century competencies through physical education: a Singapore experience. Asia Pacific Journal of Education, Vol. 4. 483-499. March 29, 2019. https://www.tandfonline.com/doi/abs/10.1080/02188791.2017.1386089.

Ljoså, E. (1998). The role of university teachers in a digital era. European Journal of Open, Distance and E-Learning, Vol. 1. March 5, 2019. http://www.eurodl.org/materials/contrib/1998/eden98/Ljosa.pdf.

Marcus, J. (2011). US Unplugged: Manifold Benefits of Disconnected Learning. Times Higher Education, Ed. 2.

Means, B., Toyama, Y., Murphy, R., Bakia, M., \& Jones, K. (2009). Evaluation of evidence-based practices in online learning: A meta-analysis and review of online learning studies. Vol. 2. March 5, 2019. http://repository.alt.ac.uk/629/

Mollin, S. (2006). English as a Lingua Franca: A New Variety in the New Expanding Circle? Journal Nordic Journal of English Studies. Vol. 5 41-57.

Moore, L. (2012). Millenials in Social Work Field Education. Journal of Field Educator. Vol. 2. December 3, 2019. https://pdfs.semanticscholar.org/7e60/352a8699f73bb6401a53b077b8217d9aa8 10.pdf.

Palocsay, S. W., White, M. M., \& Zimmerman, D. K. (2004). Interdisciplinary collaborative learning: Using decision analysts to enhance undergraduate international management education. Journal of Management Education, 28(2), 250-259. December 3, 2019. https://journals.sagepub.com/doi/pdf/10.1177/1052562903261040.

Poon, L. K., Kong, S. C., Yau, T. S., Wong, M., \& Ling, M. H. Learning Analytics for Monitoring Students Participation. [ Online]. Visualizing Navigational Patterns on Learning Management System. Presented in International Conference on Blended Learning .

Prensky, M. (2001). Digital natives, digital immigrants part 1. On the horizon, 9(5), 16. March 5, 2019.: https://www.marcprensky.com/writing/Prensky\%20\%20Digital\%20Natives, \%20Digital\%20Immigrants\%20-\%20Part1.pdf. 
Selwyn, N. (2016). Digital downsides: exploring university students' negative engagements with digital technology. Teaching in Higher Education, 21(8), 1006-1021.

Shariman, T. P. N. T., Razak, N. A., \& Noor, N. F. M. (2012). Digital literacy competence for academic needs: An analysis of Malaysian students in three universities. March 25, 2019. Procedia-Social and Behavioral Sciences, 69, 1489-1496. https://core.ac.uk/download/pdf/82032669.pdf .

Susskind, R. E., \& Susskind, D. (2015). The Future of the Professions: How Technology Will Transform the Work of Human Experts. Oxford University Press, USA.

Tan, E. (2013). Informal Learning on Youtube: Exploring Digital Literacy In Independent Online Learning. Learning, Media and Technology. Vol. 4., 463477.

Tapscott, D. (2008). Grown Up Digital. Boston: McGraw-Hill Education.

Technology, O. o. (2017). Reimagining the Role of Technlogy in Education. Washington: US Department of Education. 